\title{
Fungsi Pendidikan Kewarganegaraan Sebagai Pertahanan Nasional
}

\author{
Rindi Rendiyawati ${ }^{1}$, Dinie Anggraeni Dewi ${ }^{2}$ \\ ${ }^{1,2}$ Pendidikan Guru Sekolah Dasar, Universitas Pendidikan Indonesia \\ Jl. Pendidikan No.15, Cibiru Wetan, Cileunyi, 40625, Bandung, Jawa Barat, Indonesia \\ Rindirendiy0@upi.edu
}

\begin{abstract}
This study aims to provide an overview of how to maintain national defense among young people, knowing that now many young people do not care about the rules. The research method uses a quantitative approach with a case study method. Research informants are doing a google form questionnaire where students fill out a questionnaire that is already available and the researcher presents the results of the google form. This success from the point of view of Citizenship Education (PKN) is the development of civic virtue which is the estuary of the PKN learning objectives. Citizen virtue in the form of defending national defense among students.
\end{abstract}

Keywords: Students. Defense, Development, Quantitative Method

\begin{abstract}
Abstrak
Penelitian ini bertujuan memberi gambaran tentang cara menjaga pertahanan nasional dikalangan anak muda, mengetahui sekarang banyak anak muda yang tidak memperdulikan peratu. Metode penelitian menggunakan pendekatan kuantitatif dengan metode studi kasus. Informan penelitian yaitu melakukan kuosioner google form dimana mahasiswa mengisi kuesioner yang telah tersedia dan peneliti mempresentasekan hasil dari google form tersebut. Keberhasilan tersebut dari sudut pandang Pendidikan Kewarganegaraan (PKN) merupakan pengembangan kebajikan warga negara (civic virtue) yang menjadi muara dari tujuan pembelajaran PKN Kebajikan warga negara dalam bentuk mempertahankan pertahanan nasional dikalangan mahasiswa.
\end{abstract}

Kata Kunci: Mahasiswa. Pertahanan, Pengembangan, Metode Kuantitatif

Copyright $\odot 2021$ Rindi Rendiyawati, Dinie Anggraeni Dewi

$\triangle$ Corresponding author: Rindi Rendiyawati

Email Address: Rindirendiy0@upi.edu (Jl. Pendidikan No.15, Cibiru, Wetan, Cileunyi, Bandung)

Received 22 March 2020, Accepted 24 April 2020, Published 30 April 2021

\section{PENDAHULUAN}

Pendidikan kewarganegaraan adalah pendidikan yang mengajarkan kita memahami akan penting nya nilai-nilai dan hak kewajiwan warga Negara. Setiap hal yang kita dilakukan harus sesuai dengan tujuan dan cita-cita bangsa agar tidak melenceng dari apa yang diharapkan. Pendidikan kewarganegaraan ini adalah suatu program dalan pendidikan yang berintikan pada demokrasi politik yang mejadi luas dengan sumber pengetahuan lainnya,baikdalam pengaruh positif dari pendidikan disekolah, masyarakat, orangtua,dan semua ini bertujuan untuk melatih siswa agar memiliki pemikiran yang kritis,mampu menganalisis, mampu bersikap serta bertindak demokratis dalam menjalankan kehidupan yang berlandaskan pada pancasila 1945. Pada dasarnya, ketahanan nasional itu sangat penting dan memiliki hubungan yang berkaitan dengan kepribadian bangsa. Kepribadian bangsa ini menjadi suatu modal dari ketahanan pribadi oleh setiap individu, sampai kepribadian bangsa itu dapat dikembangkan agar terwujudnya suatu ketahanan nasional. Setiap individu sangat diharapkan agar mampu menanamkan suatu kepribadian yang mencerminkan pada pancasila (soedarsono, 1997: 52-53) ,agar bisa mewujudkan cita-cita suatu bangsa Indonesia. Dimensi yang 
dapat diukur seperti itu adalah patriotisme, optimisme, sosial integrasi, dan kepercayaan politik. Keempat dimensi ini merupakan pengukuran praktis ketahanan nasional yang ditarik dari perspektif modal sosial. Kapasitas masyarakat untuk beradaptasi dengan kemalangan dibatasi dalam penerimaan sosial pilihan untuk adaptasi (Adger, 2003: 388). Jadi, kebulatan suara atau setidaknya luas kesepakatan mengenai kebijakan nasional menuju keamanan penting dalam mengevaluasi kapasitas penduduk untuk menyerap kesulitan tak terduga atau yang sedang berlangsung. Dengan kata lain, kami menyarankan bahwa ketahanan nasional harus diukur sesuai dengan sikap politik psikologis seperti kekuatan demokrasi dan kepercayaan dalam kepemimpinan daripada hanya mengandalkan pada dimensi perilaku dan mental individu dalam masyarakat

\section{METODE}

Penelitian ini menggunakan penelitian kuantitatif dengan metode deskripsi dimana peneliti memberikan kuosioner berbentuk google form dan mahasiswa mengisi sesuai pemahaman masing-masing, mengapa mengambil google form, karena melihat situasi sekarang dimana wabah covid-19 masih menjadi penghambat untuk tidak melakukan penelitian langsung terjun kelapangan jadi peneliti memakai jalan alternative untuk melihat pemahaman mahasiswa mengenai pertahanan nasional, dimana disini peneliti mengambil 15 mahasiswa untuk dijadikan bahan uji pada penelitian kali ini.

\section{HASIL DAN DISKUSI}

Ketahanan berasal dari asal kata "tahan" yang maksudnya tahan menderita, tabah kuat, dapat menguasai diri, tidak kenal menyerah. Ketahanan berarti berbicara tentang perihal kuat, keteguhan hati, atau ketabahan. Jadi ketahanan Nasional adalah perihal kuat, teguh, dalam rangka kesadaran, sedang pengertian nasional adalah penduduk yang tinggal disuatu wilayah dan berdaulat. Dengan demikian istilah ketahanan nasional adalah perihal keteguhan hati untuk memperjuangkan kepentingan nasional.Pengertian Ketahanan Nasional dalam bahasa Inggris yang mendekati pengertian aslinya adalah national resilience yang mengandung pengertian dinamis, dibandingkan pengertian resistence dan endurence. (ahmad syafi'I : 2004).

Jika kita mengkaji Ketahanan nasional secara luas kita akan mendapatkan tiga "wajah" Ketahanan Nasional, walaupun ada persamaan tetapi ada perbedaan satu sama lain seperti:

1. Ketahanan Nasional sebagai kondisi dinamis mengacu keadaan "nyata riil" yang ada dalam masyarakat, dapat diamati dengan pancaindra manusia. Sebagai kondisi dinamis maka yang menjadi perhatian adalah ATHG disatu pihak dan adanya keuletan, ketangguhan, untuk mengembangkan kekuatan nasional dalam mengatasi ancaman. 
2. Ketahanan nasional sebagai konsepsi pengaturan dan penyelenggaraan negara diperlukan penataan hubungan antara aspek kesejahteraan (IPOLEKSOSBUD) dan keamanan (Hankam). Dalam konsepsi pengaturan ini dirumuskan ciri-ciri dan sifat-sifat ketahanan nasional, serta tujuan ketahanan nasional.

3. Ketahanan Nasional sebagai metode berfikir, ini berarti suatu pendekatan khas yang membedakan dengan metode berfikir lainnya. Dalam ilmu pengetahuan dikenal dengan metode induktif dan deduktif, hal ini juga dalam ketahanan nasional, dengan suatu tambahan yaitu bahwa seluruh gatra dipandang sebagai satu kesatuan utuh menyeluruh.

\section{Metode Astagrata}

Dalam usaha mencapai tujuan kita senantiasa menghadapi ancaman, tantangan, hambatan, dan gangguan. Sehingga kiperlukan ketahanan yang mengandung kemampuan untuk mengembangkan kekuatan nasional. Sebagai manusia yang berbudaya yang mengadakan hubungan dengan alam sekitarnya dalam usaha mempetahankan eksistensi kelangsungan hidup. Sering kita kenal hubungan-hubungan seperti itu dengan

1. Dalam "agama" yaitu adanya suatu hubungan antar umat manusia dengan sang pencipta atau tuhannya.

2. Dalam "Ideologi"yaitu adanya hubungan manusia dengan sebuah cita-cita yang hendak untuk mencapai sebuah tujuan dalm kehidupan.

3. Dalam "Politik" yaitu adanya hubungan antar manusia atau rakyat dengan pemimpin dan penguasan di negara.

4. Dalam "ekonomi" yaitu adannya hubungan antara manusia dengan sebuah kebutuhan yang digunakan dalam memenuhi keperluan.

5. Dalam "Sosial" yaitu hubungan antara manusia dengan manusia lainnya dalam berkehidupan yang sosial.

6. Dalam "Seni atau Budaya"yaitu adanya hubungan antara manusia dengan suatau karya yang bersifat indah dan menarik.

7. Dalam "IPTEK" yaitu adanya hubungan antara manusia dengan alamnya yang memiliki fungsi dan manfaat dalam kehidupan manusia.

8. Dalam "Hankam" yaitu adanya hubungan antara manusia dengan rasa aman, hal tersebut dapat ditunjukkannya adanya badan hukum serta peraturan yang berlaku dalam sebuah negara

Hubungan manusia dengan lingkungan nya itu sangat lah penting dan bisa membantu untuk emmenuhi kebutuhan hidup agar menjamin kesejahteraan dan keamanan hidup suatu bangsa. Pada hakikatnya ketahanan nasional itu merupakan sebuah konsep dalam pengaturan dan penyelenggarakan kesejahteraan dan keamanan yang selaras dikehidupan nasional. Ada dua aspek 
dalam ketahanan nasional ada aspek alamiah dan aspek social, aspek alamiah meliputi : posisi lokasi geografi, keadaan dan kekayaan alam, dan kemampuan penduduk. Selanjutnya pada aspek sosial meliputi: ideology, politik, sosial budaya, dan pertahanan keamanan.

\section{Aspek Trigatra}

Aspek trigatra ini mempunyai posisi dan lokasi geografi Negara yang secara geografis nya merupakan wujud Negara seperti, ada Negara daratan : laos, swiss, afganistan. Negara daratan dengan sebagian perairan lautnya: seperti irak, brunei Darussalam. Negara pulau: seperti Australia, malagasari. Dan Negara kepulauan (archipelagic state) contohnya seperti Indonesia.

\section{Aspek Pancagatra}

\section{Aspek Ideologi}

Pengertian ideologi diartikan isebagai (guiding iof iprinciples) iyang idijadikan idasar iatau pemberi iarah idan itujuan iyang ihendak idicapai idalam imelangsungkan idan imengembangkan hidup idan ikehidupan insional isuatu ibangsa i(negara). iIdeologi iadalah iilmu ipengetahuan tentang idasar iatau idapat idisamakan idengan icita-cita. iDengan ilain iperkataan ibahwa ideologi imerupakan ikonsep iyang imendalam imengenai ikehidupan iyang idicita-citakan iserta yang iingin idiperjuangkan idalam ikehidupan inyata i(Endang iZaelani iSukaya, i2000: i105).

Agar iBangsa indonesia imemiliki iketahanan idi ibidang iideologi imaka iPancasila iharus dijadikan ipandangan ihidup ibangsa, idan idiperlukan ipengamalan iPancasila isecara iobyektif dan isobyektif. iSemakin itinggi ikesadaran isuatu ibangsa iuntuk imelaksanakan iideologi, maka akan isemakin itinggi iketahanan idi ibidang iideologi. iDalam i istrategi ipembinaan iideologi ada ibeberapa i iprinsip iantara ilain:

1. Ideologi harus diaktualisasikan dalam bidang kenegaraan dan oleh WNI.

2. Ideologi sebagai iperekat ipemersatu harus ditanamkan ipada iseluruh WNI.

3. Ideeologi harus dijadikan panglima bukan sebaliknya

4. Akatualisasi ideologi dikembangkan ke arah keterbukaan idan ikedinamisan.

5. Ideologi iPancasila imengakui ikeanekaragaman idalam i ihidup iberbangsa, idan idijadikan ialat imenyejaterakan, imempersatukan imasyarakat.

6. Kalangan elit eksekutif, legeslatif, yudikatif, harus imewujudkan icita-cita ibangsa idengan melaksanakan GBHN, mengedepankan kepentingan bangsa.

7. Mensosialisasikan idologi Pancasila sebagai ideologi humanis, religius, demokratis, nasionalis, berkeadilan. Proses sosialisasi Pancasila secara obyektif, ilmiah bukan doktriner, dengan metode sesuai dengan perkembangan jaman.

8. Tumbuhkan sikap positif terhadap warga negara dengan meningkatkan motivasi untuk mewujukan cita-cita bangsa. Perlunya perbaikan ekonomi untuk mengakhiri krisis moltidemesional (Endang Zaelani Sukaya, 2000: 109).

Dari hasil penelitian saya menggunakan google form, saya menarik hasil hampir semua mahasiswa mengetahui apa itu pertahanan nasional. Dapat kita lihat diagram pada gambar 1 . 


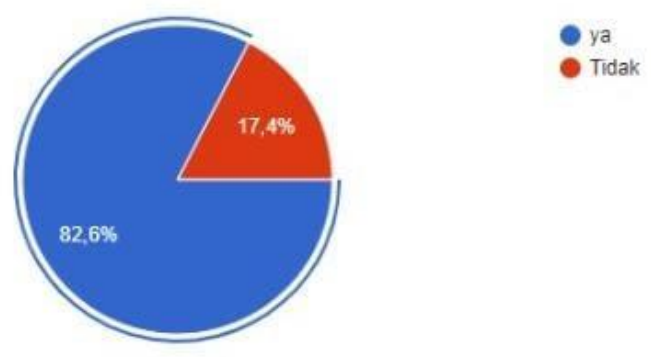

Gambar 1. Hasil Jawaban Siswa terkait Pertanyaan pertahanan Nasional

Kasus yang terjadi di indonesia yang mengancam sistem pertahanan nasional tidak kalah menarik banyak kasus yang menjadi ancaman dalam pertahanan nasional di indonesia, kita bisa lihat pada diagram lingkaran yang ada di gambar 2 .

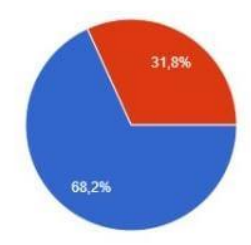

: ya

\section{Gambar 3. Hasil Jawaban Peserta Didik}

Dan contoh kasus mengenai sistem pertahanan nasional yang ada diindonesia amat sangat banyak hal itu dapat kita lihat dari contoh-contoh kasus yang mahasiswa isi di google form yang telah saya buat. Kita bisa lihat contoh-contoh kasus yang terjadi di Indonesia yang mahasiswa ketahui, ada pada gambar 3 .

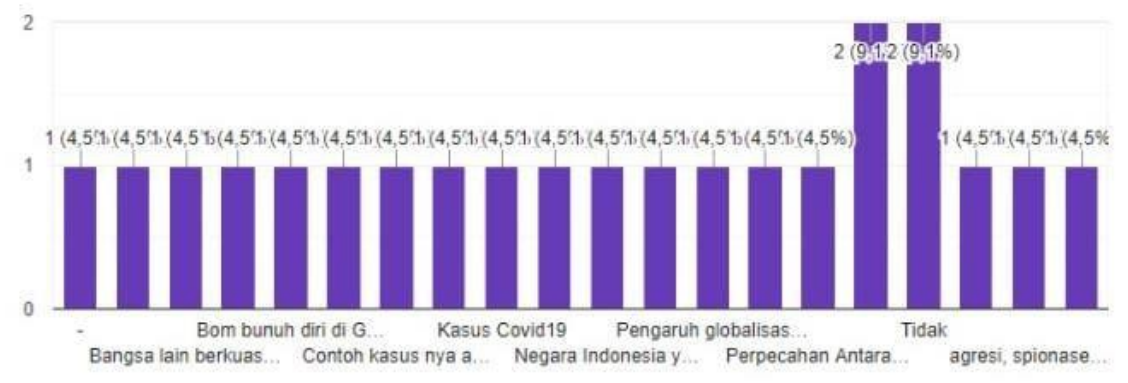

Gambar 4. Rekapitulasi Google Form

\section{KESIMPULAN}

Setiap bangsa Negara mempunyai arah tujuan dan cita-cita nya, jika tujuan dan citacita itu tercapai maka Negara itu bisa dikatakan berhasil dalam segala aspek yang dicitacitakan menuju kearah sempurna. Tujuan bangsa Indonesia telah tercantum pada UUD 1945, dalam usaha mencapainya banyak mengalami hambatan, tantangan, dan ancaman oleh karena itu perlu kekuatan/pertahanan Negara untuk mewujudkan. Ketahanan nasional perlu kita bina terus menerus dan dikembangkan agar kelangsungan hidup bangsa tersebut bisa terjamin mulus. Sejarah ketahanan bangsa, ketahanan bangsa Indonesia telah teruji, dalam sejarah 
perjuangan ketahanan bangsa Indonesia itu telah teruji, Indonesia bisa mengusir Negara-negara yang pernah menjajah seoerti jepang, belanda, danyang lainnya. NKRI tetat berdiri tegak karena memiliki daya tahan dalam menghadapi seperti ancaman,tantangan, hambatan, dan gangguan (ATHG). Bangsa Indonesia menghadapi permasalahan $\mathrm{KKN}$, krisis moneter, kemiskinan, pengangguran, konflik SARA, pelanggaran HAM, SDM yang rendah, globalisasi, namun hanya dengan ketahanan bangsa saja kelangsungan hidup bisa terjamin.

\section{UCAPAN TERIMAKASIH}

Terima kasih saya ucapkan kepada mahasiswa UPI kampus cibiru yang sudah berkenan mengisi kuosioner, dan tak lupa kepada editor pubhliser dan kakak-kakak yang sudah membimbing saya sampai saya bisa lolos seleksi dalam pem published. Tanpa dukungan dan dorongan dari kalian tidak mungkin saya bisa menyelesaikan tugas ini dengan baik.

\section{REFERENSI}

Adger, W. Neil,. (2003). Social Capital, Collective Action, and Adaptation to Climate Change. Economic Geography Journal, Vol 79. No 4.

Ahmad Syafii Maarif . (2004). "Pendidikan dan Peningkatan Moralitas Bangsa",. Pewara Dinamika, Vol 6. No 2.

Endang Z. Sukaya. dkk. (2000). Pendidikan Kewarganegaraan. Yogyakarta: Penerbit Paradigma.

Hans J. Morgenthau,. (1990). Politik Antar Bangsa. Jakarta : Yayasan Obor Indonesia.

Huntington, Samuel. (2003). Prajurit Dan Negara: Teori dan Politik Hubungan Militer-Sipil. Jakarta:

Grasindo.

Kementrian Pertahanan RI Dirjen Strahan. (2011). KebiJakan China terhadap Konflik Laut .

Lemhanas. (1995). Kewiraan Untuk Mahasiswa, Dirjen Dikti Depdikbud. Jakarta: PT Gramedia Pustaka Utama.

Soedarsono, S. (1997). Ketahanan Pribadi Dan Ketahanan Keluarga Sebagai Tumpuan Ketahanan Nasional. Jakarta: PT Intermasa.

Sumarsono, d. (2001). Pendidikan Kewarganegaraan . Jakarta: PT GRamedia Pustaka Utama. 